\title{
Karl Popper and the Social Sciences
}

\author{
Sylvain K. Cibangu \\ Regis University, Denver, \\ University of Washington, Seattle, \\ USA
}

\section{Introduction}

The social sciences have a rich tradition, as shown by its various authors and theories found throughout written history. In the 1st century BC, for example, Seneca the younger stated that "human beings are social animals" (Cl.1.3.2). Not long before, in the 4th century BC, Aristotle insisted that "man is by nature [emphasis mine] a political animal" (Pol. 1.1.9). This chapter focuses on Karl Popper, a contemporary social thinker. Popper represented one of, if not, the most prolific authors that articulated the status of the social sciences. While Popper (1950/1971a, 1950/1971b, 1959/1992, 1963, 1972, 1982, 1983, 1991, 1996a) produced an extensive body of literature devoted to the social sciences, he has been given too little attention in modern social science historiography. Even though he "concentrated mainly on practical problems of the methodology of the social sciences" (Popper, 2008, p. 87), textbooks of social science methodology rarely include Popper's writings. Consequently, his works on the social sciences and/or psychology, including his dissertation, remain largely unknown.

This chapter explores the heretofore unexplored social themes that arise and recur in Popper's writings. To begin to redress this gap in the Popperian scholarship, Popper's (2008) recently published posthumous work is of particular interest to our discussion. I pay close attention to parts IV and V of this milestone book, which contains several of Popper's unpublished materials concerned with social issues. These materials were collected from various archives preserved respectively at Stanford University (USA), University of Canterbury (New Zealand), and Klagenfurt University (Austria). In addition, Popper's correspondence with the philosopher Rudolf Carnap (see Carnap's archives at the University of Pittsburg, USA) are included. Because the scope of this project is limited, further work is necessary, especially publication aimed at unearthing Popper's materials that are housed at the London School of Economics and Political Science. Indeed, the entire catalog of Popper's archived work represents an enormous amount of unpublished materials that cannot be adequately or faithfully reproduced in a single book chapter. It is important to warn the reader that Popper's oeuvre, and in fact, all his books (perhaps with the exception of Furschung der Logic) are comprised of a mélange of papers and drafts, written in a variety of genres, including lectures, correspondences, conference presentations, and drafts. Even though the majority of his work was written in English, each text was written under different circumstances, at different times, and for different purposes. 
With such a prodigious catalog to take into consideration, a thematic approach makes the most sense. I have therefore made efforts to focus on Popper's themes that respond to the goals and scope of the present book chapter. Along the same lines, it is worth noting that "Popper's work has been among the most controversial, and influential, in twentiethcentury philosophy" (Catton \& Macdonald, 2004, p. 1). It follows that my aim is not to provide a complete explication of Popper's work, but instead, I offer an introduction/invitation to Popper's often forgotten contributions to the social sciences. After a quick biographical sketch, five key concepts will guide our reflections: (a) Popper and the world, (b) Popper and the social sciences, (c) Popper and society, (d) Popper and science, and (e) practical considerations.

A recent biography of Popper's life (Hacohen, 2000; Popper, 2008) sheds light on the underlying motivations of his work. Popper (1902-1994) was born and grew up in Vienna in an upper-class family, although neither of his parents were Austrian. His father was a Czech lawyer who settled in Vienna; his mother was Hungarian. Though they were Jewish, the family converted to Lutheranism. In 1928, Popper obtained his PhD at the University of Vienna in psychology of thinking, under the supervision of Karl L. Bühler (1879-1963). Bühler was the leading figure of Gestalt psychology at the time (ter Hark, 2003, 2004a, 2004b, 2006, 2009), which greatly influenced the development of Popper's social reflections. When the Nazis took power in 1937 in Germany, Popper migrated to New Zealand where he taught at the University of Canterbury in Christchurch. In 1946 at the close of World War II, he returned to Europe, and took a post at the London School of Economics and Political Science (University of London), and later he held several teaching positions in the US. Popper had a difficult life in Austria where he didn't feel at home: indeed, he lived as a foreigner for most of his life, and in 1994, he died as a foreigner as well in the outskirts of London. Discouraged by publication challenges, he was virtually unknown in academia and to the general public. These hardships are important to bear in mind in order to best understand his thoughts and writings. More precisely, the struggles for survival and the Nazi extermination of ideas, institutions, and populations foreground Popper's thoughts and works.

\section{Popper and the world}

To understand Popper's social theories, it is necessary to grasp his foundational ideas about the world (Popper, 1959, 1988). Popper distinguished three groups of worlds: (a) the physical world (world 1), which is the exterior and cosmic world, (b) the world of mental states and subjective knowledge (world 2), and (c) the world of social and recorded knowledge (world 3). World 1 concerns the cosmos and accompanying physical forces. World 2 involves the mental and subjective experiences of humans and the minds and feelings of animals. World 3 embraces social phenomena, namely: culture, language, laws, customs, and institutions, all of which are found in a recorded form of knowledge (e.g., utensils, houses, books, masks, tablets, and the like). Though interrelated, the three worlds are each autonomous and objective in that they can be tested and demonstrated independently from the subject. The tripartite cosmology provides the groundwork from which to understand the Popperian division of sciences. Inexplicably, authors tend to understand Popper's classification of sciences separately from his worldview, although these classifications are essential to understanding his social tenets as well. We will discuss the characteristics of science and social sciences below, but for now, note that the natural 
sciences are conceived of as belonging to world 1, whereas the human and social sciences correspond to world 2 and world 3, respectively.

Even though each of the three worlds designates particular categorical qualities, each world can be connected with the same object at different levels. To illustrate, a book can be considered as a physical object, and for that reason the book belongs to world 1. As a physical object, the book, consisting of paper, ink, illustrations, and a cover, manifests a series of physical properties of the cosmos. However, the meaning of the printed words, as well as any comments and annotations made in the book, belong to world 2, since they represent the mental states of the author and readers, which correspond to a series of physical forces/entities. The content of the book is conveyed through forms of recorded knowledge (e.g., alphabet, paragraphs, and chapters, etc.), which belong to world 3. Recorded knowledge represents specific social institutions, such as publishing houses, libraries, universities, research centers, and nations, with each one performing specific activities, complete with their own force, and each of these social institutions operates within and through specific facilities. Popper envisaged a world 4, comprised of arts and related objects, although he came to include its material in world 3 since art represents recorded knowledge. For Popper (1988), all the worlds together in aggregate form are an open universe-a universe of indeterminism, with unrestricted freedoms and unrestrictive theories. For this reason, Popper characterized scientific work through the rubric of its contributions to the world.

We will discuss the idea of open universe when we get to the concept of society, for now bear in mind that, as pointed out above, the three worlds pave the way to the classification of sciences.

\section{Popper and the social sciences}

In his later works, Popper (1991, 1996a, 1996b, 2008) devoted expansive and in-depth literature to describe the human and social sciences. Popper understood the social and human sciences to be interchangeable in order to best defend their scientific character, which is commonly thought to be subjective, weak, non-measurable, etc. (see Little, 1998; Rosenberg, 2008; Wallerstein et al., 1996). ${ }^{1}$ In Popper's logic, three dominant concepts characterize the social sciences as: (a) scientific, (b) objective, and (c) empirical. First, Popper understood the social sciences as sciences in the full sense of the word, a position that attempts to refute the widespread idea that the social sciences represent a weak form of science. Discussions of the scientific status of the social sciences (their methods, theories, and laws) are usually impaired by the common misunderstandings that authors entertain about physics and its laws. The point behind those misunderstandings is that

physical laws, or the "laws of nature", are valid anywhere and always; for the physical world is ruled by a system of physical uniformities invariable throughout space and time. Sociological laws, however, or the laws of social life, differ in different places and periods. (Popper, 1991, p. 5)

Popper's statement critiques the view that physical laws are more universal than the laws of social life. This view lacks empirical evidence and reveals a restricted understanding of both

${ }^{1}$ For further discussion about the difference between the human and social sciences see Cibangu (2010b). 
the cosmos (world 1) and the social world (world 3). Remember that all three worlds are made of autonomous and objective physical entities. The laws of physics are the same in each of the three worlds. Therefore, by the virtue of their object of study, the social sciences are objective. Popper (1991) elaborated, "although historicism admits that there are plenty of typical social conditions whose regular recurrence can be observed, it denies that the regularities detectable in social life have the character of the immutable regularities of the physical world" (p. 5). One needs to bear in mind that historicism in the Popperian sense is different from that encountered in social science literature. According to Popper (1991, 1971a), historicism states that human history involves regularities and patterns with which the evolution of society can be understood and predicted. In this sense, historicism simply means evolutionism. ${ }^{2}$ The social sciences seek to pinpoint the regularities hidden in the physical processes of the social world with the goal of crafting newer problems and newer theories. Popper (1996b) explained,

The method of the social sciences, like that of the natural sciences, consists in trying out tentative solutions to those problems from which our investigations start. Solutions are proposed and criticized. If a proposed solution is not open to objective criticism, then it is excluded as unscientific. (p. 66)

Note how new problem-solving criticism, variedly called critical method, deductive logic, critical discussion, critical rationality, or rational criticism, characterizes all sciences, both social and natural. Certainly, scientific work involves testing proposed hypotheses and theories, while critical discussion leads to these tests.

I consider it important to identify scientific method, at least in first approximation, with the critical method... The method of science consists in the choice of problems and in the criticism of our ever tentative and provisional attempts to solve them. (Popper, 1996b, p. 74)

Criticism of encountered puzzles and suggested theories constitute the unifying method of sciences. However, this methodological foundation of sciences has been understood to indicate the uniformity of methods and disciplines. ${ }^{3}$ A quick semantic clarification may help advance the discussion. I should emphasize that the word method is an ambivalent concept found in social science literature. Not surprisingly, what Popper meant by method is often different from what authors and readers expect, and even more confusing, the term can hold fluctuating semantics within the same book. Furthermore, Popper did not supply a definition of the term, although he attempts to circumvent misunderstanding with the statement: "I do not intend to assert that there are no differences whatever between the methods of the theoretical sciences of nature and of society" (Popper, 1991, p. 120). In this specific context, thorough textual review reveals that Popper understood method as a fundamental and underlying strategy of science. Perhaps an analogy will help to illustrate method as a fundamental and underlying strategy. For example, the fundamental strategy for athletic success is competitiveness. However, while competitiveness is an underlying strategy for athletic success, it does not follow that athletic success is limited to one set of

\footnotetext{
${ }^{2}$ Some of the sources on evolutionism and Popper's historicism are Cibangu (2009) and Urbach (1985), respectively.

${ }^{3}$ See Verdugo's (2011) recent article for sustained discussion about the unity of methods according to Popper. For the use of the word method see Cibangu (2010a).
} 
rules, one set of techniques, and identical methods of scoring. The unity of fundamentals does not exclude the diversity of methods.

The second dominant concept, perhaps the most challenging in Popper's literature, is that Popper considered the social sciences to be objective. As noted earlier, Popper placed the social sciences in world 3, which contains definite physical entities/forces. These physical entities, which he also called propensities (Bächtold, 2006; Popper, 1990; Runde, 1996), confer an objective character to the social sciences. For this reason, the social sciences provide us with an objective understanding of the social world. Popper (1996b) refuted the misunderstanding that

objectivity in the social sciences is much more difficult to achieve (if it can be achieved at all) than in the natural sciences. For being objective demands that one is not biased by one's value judgments... But only in the rarest cases can the social scientist free himself from the value system of his own social class and so achieve even a limited degree of "value freedom" or objectivity. (p. 68)

Against this misunderstanding, Popper situated objectivity in a much more communal and inter-subjective sense than is usually perceived within the natural sciences, wherein the researcher is often seen as the sole center of science. Locating objectivity in an intersubjective way highlights the social world of science as necessary to ensure objectivity itself, since the exchanges that happen in such inter-subjective engagements as peer review and criticism, can filter out biases. Further, Popper rejected the idea of science that is merely a matter of personal choices and preferences, though he allowed that personal choices and preferences can potentially be part of the research process. He noted,

It is completely erroneous to believe that the attitude of the natural scientist is more objective than that of the social scientist... The objectivity of science is not a matter for the individual scientist, but rather the social result of mutual criticism, of the friendlyhostile division of labour among scientists, of their co-operation and also of their competition... Objectivity can only be explained in terms of social ideas such as competition (both of individual scientists and of various schools of thoughts); tradition (that is the critical tradition); social institutions (for instance, publications in various competing journals and by various competing publishers; discussions at congresses); the power of the state (that is, its political tolerance of free discussion). (1996b, pp. 72-73)

Objectivity, then, is not a goal in and by itself, nor the achievement of an individual scientist, but a nest of autonomous, objective, and physical entities of world 3, namely: communities, groups, institutions, and venues that criticize the researcher's proposed theories. Objectivity derives from the combination of these social and physical forces. In other words, objectivity is the byproduct of critical inter-subjectivity such that the subject does not command on his/her own. As explained earlier, the social world carries physical forces with it. Most pertinently, Popper referred to verstehende Soziologie (see Cibangu, in press), as a sociology of objective understanding. Objective understanding rests on the hermeneutic tradition of inter-subjective interpretations and criticisms, the product of which is not bound to an individual's opinions and preferences.

Social institutions determine the peculiarly social character of our social environment. They consist of all the social realities of the social world, realities which correspond to 
the things of the physical world. A grocer's shop or a university institute or a police force or a law are, in this sense, social institutions. (Popper, 1996b, p. 80)

Just as objective statements of the natural sciences involve physical entities of world 1, objective statements of the human and social sciences also involve the physical entities of world 2 and world 3, respectively. The social entities embody the fabric of inter-subjective exchanges, of which the social sciences endeavor to show the (objective) understanding. To be clear, a more telling expression with which to determine objective understanding might be that of trans-subjective undertakings. The understanding obtained in the social sciences is one that reflects a trans-subjective (i.e., beyond-subjective) reality.

The third and last concept that characterizes the social sciences is empirical (Popper, 1959; Shearmur, 2006). While doubt can be raised as to whether the social sciences are empirical or non-empirical, Popper classed the social sciences as empirical. A close look reveals that Popper held two major lines of thought as to what constitutes an empirical approach. On the one hand, Popper understood empirical sciences in the traditional sense; that is, the sciences that deal with experiment and observation, using induction as their sole method of analysis. Also called applied sciences, these represent the sciences that Popper was most critical of. The traditional sense of empirical sciences reflects the 17-19th-century model that depicts science as a replication of natural laws and theory as a non-sense. On the other hand, Popper took the empirical sciences as ones that go beyond the limitations of inductivism. Popper's view heralds the methodology of modern empirical sciences. Popper rejected inductivism as the conduit of universal truths. Popper's now canonical example of inductive reasoning is helpful here: imagine that a researcher observes all of the swans in the world, and one by one, found that every swan is white. According to induction, the researcher is allowed to conclude that all swans are white: the conclusion is therefore valid, since it proceeds from a higher number of observed particulars to a universal statement. Popper found such typical inductivist conclusions implausible. Even if the researcher has found by inductive experiments that all observed swans are white, the veracity of the statement, all swans are white, is not guaranteed. In other words, the conclusion that all swans are white is simply a situational statement, not a universal truth. For example, there may have been red swans two millennia ago, or, there may be grey swans in the future, or there may be brown swans in a location unknown to the researcher. This shows that experimental inductivism is always context-bound and cannot lead to universal truths.

Because observation is limited, researchers use deductive reasoning, applying principles of logic to come to a conclusion. However, with deductive logic or deductive induction, particular statements lead to a particular understanding of the situation at hand. Logic deals with the case analysis of particular situations (see Cibangu, in press). At the same time, deductive logic can lead to statements that are stronger about, and nearer to the truth, than are the statements derived from, and limited to observational context. In this respect, the second kind of empirical sciences involve deductive logic through the test of theories. Popper understood deductive logic to be the characteristic of science. The scientists' role "is to analyse their logical consequences [of statements]: to point out their fertility - their power to elucidate the problems of the theory of knowledge" (Popper, 1959, p. 38). Even though induction and deduction are inadequate on their own, Popper showed that in combination at the logical, not experimental, level, they lead to stronger conclusions and stronger methodologies. Putting both kinds together, Popper (1959) viewed empirical sciences as 
ones that engage experiment and/or the testing of theories. The endeavor to test theories consists of critically/logically confronting them with empirical evidence. Empirical evidence represents the real world with which humans are confronted. Context-bound observation (inductivism) tends to limit the real world. In essence, empirical sciences are characterized by the following scheme: problems, theories, criticisms, and new problems (see Popper, 1996a, p. 158). The goal is to suggest new paths of research. Though concerned with experience and experiment, empirical is not the end product of science. Science is earmarked by the process of forging newer and newer theories.

One of the most misled tendencies among authors is to view empirical and theoretical concepts as opposite and exclusive. Hence, one would think that the empirical sciences are best undertaken when one avoids the theoretical dimension of research. However, Popper (1996b) noted, "there is no such thing as purely observational [empirical] science; there are only sciences in which we theorize (more or less consciously and critically). This also holds true for the social sciences" (p. 78). Theories represent the hallmark of the empirical sciences, and of all sciences. Modern empirical or applied sciences involve a great deal of theorization. Empirical science simply means that theories are tested and applied in particular circumstances, and under particular forces of the social world. To further highlight the characteristics outlined above, Popper identified one method to be unique to the social sciences, which he referred to as the method of objective understanding, or, alternately, situational logic. The method springs from the idea of objective understanding attributed to the social sciences. Popper (1996b) explained,

The logical investigation of the methods of economics yields a result which can be applied to all social sciences. This result shows that there is a purely objective method in the social sciences, which may well be called the method of objective understanding, or situational logic... Objective "understanding" consists in realizing that the action was objectively appropriate to the situation... Situational logic assumes a physical world in which we act. [emphasis in original] (pp. 79-80)

Objective understanding takes us into a world-like environment, the patterns and regularities of which embody logic and/or meaning. The researcher is called to analyze the logic and meaning of the selected situation within the social world.

Situational analysis is Popper's attempt to overcome the interpretive-positivistic divide. Popper (1996a) explained that, "the fundamental problem of the social sciences is to explain and understand events in terms of human actions and social situations. The key term here is 'social situation' [emphasis in original]" (p. 166). Clearly, Popper was of the opinion that both interpretive and positivistic knowledge are needed in order to disentangle the human actions and the physical entities hidden in the situation at hand. Situational analysis transcends the interpretive-positivistic divide, since "the situational analysis will comprise some physical things and some of their properties and states, some social institutions and some of their properties, some aims, and some elements of knowledge" (Popper, 1996a, p. 168). Note the notion of properties (i.e., autonomous physical forces or entities discussed earlier) along with the social and human elements. Certainly, these physical forces imply objective knowledge. With the objective understanding of the patterns behind lived experiences and phenomena, interpretivism goes far beyond the ability to interpret meaning and text, and draws on broader (inter-subjective) independent forces. Situational analysis is a model with which to interpret the patterns hidden beneath 
phenomena. While Popper (see 1996a, p. 173) wished to consider situational analysis as the property of the social sciences (Gorton, 2006), situational analysis presents all the right ingredients for the natural sciences as well (e.g., objective, logic, test, hypotheses, experience, etc.). The characteristics of the social sciences seen above make this method of the social sciences a strong candidate for the natural sciences.

Closely related to situational analysis is the concept of methodological individualism. Although strongly supported by Popper, methodological individualism is neither Popper's (1971a, 1971b) concept nor his theory. The method can be traced as far back as to Aristotle's (4th c. BC, 1924) idea that professions and their organizations correspond to human needs. Methodological individualism serves as a channel of objectivity (i.e., inter-subjective exchanges) that situational analysis claims to bring. The idea is that social science objectivity does not seek to supplant individual agency and related particular entities in the name of social collective forces and structures. Therefore, methodological individualism rejects totalitarianism and collectivism (Chalmers, 1985; Gonzalez, 2004). Methodological individualism constitutes in part a response to Gestalt psychology which teaches that the brain as a whole provides explanation for all specific human sensations (i.e., vision, touch, smell, taste, and hearing). Furthermore, Popper's extensive rebuttal against psychologism, is foundational to his social teachings -- a body of work that is largely unknown and remains unpublished (ter Hark, 2003, 2004a, 2004b, 2006, 2009). Popper presented a context-specific explanation of human sensorial phenomena distinct from psychologism. The three worlds, the physical, the mental, and the social, are not a mere human representation, but they each contain entities endowed with autonomous processes.

For Popper, the interpretation of social phenomena must be achieved according to specific relations between autonomous individuals, their actions, and collective bodies. Popper (2008) noted,

Collectivism is here attached to such views as that the individual is unimportant while some "collective body" such as race, or class, or nation, is all-important, if not divine, and the social sciences have to study the structure and especially the movement and the development and the history of "collective bodies". (p. 134)

The espousal of methodological individualism, in rejection of collectivism, speaks to the various hardships Popper encountered all along his life. Popper did not seek to debunk social structures, but to argue for an open society. He urged methodological individualism because "we must try to understand all collective [social] phenomena as due to the actions, interactions, aims, and thoughts of individual men, and as due to [the] traditions created and preserved by individual men" (Popper, 1991, p. 157). Stated differently, transsubjectivity does not entail totalitarian trans-plantation of a group's agendas and preferences onto the rest of humanity, rather, it can mean ongoing affirmation of individuals' agencies and needed physical entities. Trans-subjectivity implies that situational analysis is not about totality and collectivity, but the quality of individuals' lives, their actions, and needed physical entities. In addition, Popper considered academic work to be a tool for making the world a better place, since "it is, however, quite obviously the task of all thinking people to do their best to bring about a better world" (Popper, 2008, p. 289). Methodological individualism privileges each and every individual, with his/her actions, choices, and physical entities. 


\section{Popper and society}

Popper distinguished two kinds of societies; the open society is based on critical discussion about such human pursuits as achievements, decisions, goals, and authority, whereas the closed society does not allow for social criticism, and may even exterminate individuals, their ideas, and properties. Popper believed that "it [open society] introduces a new and practical view of social methodology" (Popper, 2008, p. 110), which resists closed thoughts, structures and actions. For better or worse, the widespread fixation of Popper's work on the field of philosophy of science 4 and ensuing debates has led to no small neglect of Popper's social doctrine. As his key social tenet, Popper fought for an open society, a society in which we are actors of our history and makers of our destiny. It is inexplicable that "most commentators think of Popper and his intellectual legacy primarily in terms of his philosophy of science" (Sassower, 2006, p. 7). The open society gives a markedly social tenor to the wide range of Popper's thoughts from scientific work, to knowledge and methodology.

In rebuttal against the commonly held idea that Popper's work falls exclusively under philosophy of science, Popper (2008) clarified the focus of his study, saying,

By inclination and by choice, my fields of study are the natural sciences - physics and biology - and especially their methods. Yet I came to think seriously about [the] problems of our political and social responsibilities... in my sixteenth year [he was born in 1902]... In 1938 [a year after he migrated to New Zealand], when I heard the news that Hitler had invaded Austria, my homeland, I decided to write down some of my thoughts about political freedom. (p. 355)

Certainly, social issues became the focal point of Popper's lifelong concerns. Psychology of the brain was Popper's formative field, which drew primarily on physics and biology, and left its indelible mark on Popper's understanding of social science methodology. In effect, though not always acknowledged, Popper's concepts are to be taken "as means to broad social and political ends, and not as ends in themselves" (Sassower, 2006, p. 40). In light of the dire conditions endured in Austria and beyond, open society has become Popper's overarching thesis. A closed society is characterized by abstract, repressive, uncontextualized, and disconnected truths, all of which lead to passivity, stagnation, misery, and monotony. An open society cherishes creativity and participation of all individuals.

The concept of an open society was not invented by Popper. Popper (1971a, p. 202) acknowledged that he borrowed the phrase from the French philosopher Henri Bergson (18591941). In a later statement, Popper argued that the German poet Heinrich Heine (1797-1856) used the concept open and closed society before Bergson: "Much later I found that, long before Bergson, the German poet and historian of ideas, Heinrich Heine, had also used it [open/closed society]: he described (approximately in 1850) Prussian society as closed society, and French society as open" (Popper, 2008, pp. 388-389). However, no firm evidence has been found to prove this claim (Popper, 2008, p. 478, footnote 6, see also Heine, 1840/2006). Remember that a large part of Heine's works were burned at Opernplatz (Berlin) in 1933 by the Nazis (see Micha Ullman, s.d.). Heine's words referring to the burning of books and people had been engraved at the Opernplatz (Bebelplatz) site and can be seen to this day.

\footnotetext{
${ }^{4}$ For specialized research, Gorton's (2006), Keuth's (2005), and Rowbottom's (2011) works, among others reference helpful sources regarding Popper's philosophical debates.
} 
An open society is not fixed in a specific social system, but is an ongoing journey along the lines of which we critically review our actions, theories, ideas, and structures in the hopes of enjoying fuller lives. Open society lends itself to a broader scheme of open science and open universe (Popper, 1988). In an open universe, humans can dream the highest, reach the broadest, and feel the deepest while a closed universe confines and crushes minds and hearts. The concept of open universe includes more than open dimensional space. It includes the conceptual, creative, and critical spaces for human thought and action. In addition, open universe folds in the laws of nature as the forces that fulfill and advance all individuals and their properties. For example, the more openness roses enjoy the more they radiate fragrance, but when roses endure closedness, the less they thrive. Similarly, better human lives require open space/universe for our bodies, feelings, ideas, and societies. Open universe loosens the shackles of social systems under which we struggle to survive despite financial and emotional pressures. Unrestricted freedoms and unrestrictive theories mark the difference between open science and closed science (science and non-science), open and closed world, open and closed universe, and open and closed society.

This value of openness fueled Popper's critique of historicism. Historicism teaches that a few people have "the supreme task of the great men and great nations to become actors on the stage of history" (Popper, 2008, p. 133), and it is a natural law that a given race is considered to be the chosen people and the required instrument of evolution and human destiny (Popper, 1971a). Under historicism, the rest of humanity is called to emulate the biological and human superiority of the chosen people. He also spoke of spiritual historicism in the sense that a given race is considered to be the people chosen by God and the instrument of God's will. Against this belief, Popper argued that no one group of people and race can totalize and supplant humanity and its complexity. This shows how the idea of the chosen people can also be applied to racism. One of the most forgotten tenets of Popper is his characterization of racism. Popper included racism under the umbrella of historicism (see Popper, 1971a, pp. 9-10). Methodological individualism comes in sharp contrast with racism and historicism since both impair the open society.

While it is not uncommon to defend society with the belief that a group of people are chosen whereas others are not, the belief of the chosen people is brought to greater light when humans are faced with various kinds of challenges and predicaments. At another level, Popper described historicism with the idea of economic development wherein the chosen people are presented to be the instrument of economic progress, and whose stages of development other societies ought to emulate. These days of endemic economic crisis that reel across the globe offer a perfect opportunity to witness examples of the chosen people concept. Imagine someone has been laid-off from work. The system of the chosen people is so engrained in our heads that we tend to rationalize someone's job loss by saying that the person might not be meant (chosen) for that job in that particular company. The person is thus advised to seek work elsewhere, if she can. Rarely do we argue that those who had remained in the company are not as well made to be there, or that they have to look for work someplace else. It all appears that, for better or worse, the departure of the laid-off person and the staying of the others in the company ensures a normal and stable society. With the idea of the chosen people, society becomes closed, and the ability to build, revise, and improve basic services, systems, and individuals' actions fades. An open society, however, achieves the unrestricted manifestation and fulfillment of individuals' lives and their worlds. Open society seeks to "fight against avoidable concrete evils such as avoidable 
misery" (Popper, 2008, p. 118). It does not mean that one cannot lay off a person in a reasonable manner, but that an open society endows all individuals with fuller life. All are chosen and entitled to live to the full.

As one can see, the open society calls for a full review of our thinking in order to bring about a better world for each and every human. Consequently, situational analysis's role is to criticize, affirm, and illuminate the actions, relations, values, properties, and potentials of each and every individual. An open society implies an open universe, a universe which is indeterminate in order to allow unrestrained and fuller fulfillment of individuals. This also implies an unrestrictive science which is always open and incomplete. As Popper (1996a) put it so well, "I regard freedom, political freedom as well as a free and open mind, as one of the greatest, if not the [emphasis in original] greatest, value that our life can offer us" (p. ix). The open society is a way of life, from thinking to acting to feeling to being. As mentioned above, science is not exempt from the open society.

Popper's extensive comparison of the open society with Western societies can lead people to believe that the open society must be found in Western societies. Popper (2008) wrote,

Western societies are the freest, the most tolerant, the fairest, and the least violent societies of which we know: with the exception perhaps of pre-twentieth-century Eskimo society. In this there were some cases of murder or manslaughter, but no other forms of violence, as far as we know. These Eskimos lived almost without government... The truth is that... they [Western societies] are the only societies in which there is much freedom; in which much is done for the welfare of the needy; in which there is much equality before the law, and in which there is much toleration. (p. 317)

While such a statement implies that the open society is exemplified in Western societies, there are a number of nuances to consider, from which I have selected the three most important. The first nuance is that Popper recognized the Eskimos as an exception/corrective to his understanding of society without violence. Meanwhile considerable anthropological materials show numerous non-Western societies (Lévi-Strauss, 1948; Malinowski, 1922/1984; Murdock, 1959) that had lived for centuries without major violence, repression, genocide, etc. Among others, the sense of cohesion and community is predominant in several non-Western societies. ${ }^{5}$ To illustrate, democracy is widely considered to be one of the most obvious signs of a fair society. While it has been formalized in the past few centuries in the West, democracy is not a specialized Western product. Sen (2009) wrote, "there were, in fact, several experiments in local democracy in ancient India... We have to look beyond thinking of democracy only in terms of European and American evolution" (p. 322). The signs of a fair society, such as democracy, justice, equality, and the like are deeply engrained in the hearts and minds of all humans. It doesn't mean that all societies of the world are fair, but that ideas of democracy, justice, equality, etc. are not alien to human nature nor are they reserved to a specific class/nation. This is why even within the most vicious regimes one finds voices of opposition. Sen (2009) went on, "the practice of elections, in fact, has had a considerable history in non-Western societies" (p. 330). Yearning for a better world, all societies can align perfectly with the concept of an open society. The second nuance after Popper's recognition of Eskimos is that critical

${ }^{5}$ For further discussion about community tendency in Western societies see Putnam (2000). 
discussion was prominent in several non-Western societies. For example, in the event of repeated/proven improprieties, a king could easily be deposed by a group of sages in the Luba empire in Africa (Reefe, 1981). Another example, among many, can be found in ancient India (Mookerji, 1919, Sen, 2005). Discussions about the substantial issues of daily life have preoccupied humans across cultures and times. The third and last nuance relates to Popper's (2008) clarification that "of course, our society [Western] is very far from perfect" (p. 317). As it should be clear now, the open society is a journey in which Western societies are also partaking like any other society.

Popper recognized that an open society is not fixed in a particular system, but he also emphasized that there is much work that needs to be done in Western societies. The fact that work needs to done in Western societies underlines humanity's deep-seeded search for freedom. This search is far from finished in any human society. Humans are engaged in a movement towards improvement and a better world.

Although I look upon our Western welfare state with critical eyes, I assert that we in the West have achieved a greater degree of freedom and justice than any other civilization of which we have knowledge; even though there is still too much oppression and injustice about, and even though the great hope has not been fulfilled that by combating poverty and tyranny we shall be able also to eliminate or at least reduce unhappiness, alcoholism, drug-taking, and crime. Thus although I regard our society as greatly in need of improvement and reform, I assert that we have achieved much, in spite of the many grave mistakes we have made. The evolution of our society towards a freer and more open society is not the result of impersonal historical laws. It is, I suggest, the result of a movement for freedom... This movement has its basis in a longing for freedom, and in a generous impulse of uncounted and unknown men to better the lot of their fellow men, to produce a better world. [emphasis mine] (Popper, 2008, p. 301)

An open society proves to be a vision in the direction (Western) societies are called to journey in order to improve people's destiny and make the world a better place. Western civilization is not, in and by itself, the end goal of the open society; rather the open society seeks to bring about a better world and create fuller life.

The open society does not come by the mere multiplication of nice and good-hearted individuals talented with bright dreams, but it comes by the hard work of criticizing what has been done and what ought to be done in the interest of all. "What is needed, what must be added to our dreams of a good society is, more than anything else, hard critical thinking... Hard critical thinking is painful and unpopular" (Popper, 2008, p. 289). Policies and decisions ought to be the subject of ongoing criticism in order to implement an open society. Without critical discussion, the offered basic freedoms and other social advantages become unproductive and repressive. The open society is not a gift or check generously awarded by powerfully philanthropic and/or political figure(s), but it is a way of life secured by critical thinking. Safety does not come from weapons, but from critical thinking.

Popper outlined the three principles of critical thinking as follows (Popper, 2008, p. 323):

1. I may be wrong and you may be right

2. Let us talk things over rationally

3. We may get nearer to the truth, even though we do not reach agreement 
The first principle is based on the fact that humans are prone to error, even with the best intentions. The second principle highlights the idea that errors can be corrected and appreciated through critical discussion. Error doesn't necessarily mean lack of knowledge. An error can lead to a discovery and/or stronger understanding of that which is being studied. The third principle concerns the idea of journeying, not arriving, towards the truth. Arriving means there is no longer any horizon or vision to head to and long for. We can arrive at a specific location or goal, but we will always need horizons in order to see better and farther. Popper used the concept of biological adaptability to illustrate the open society and its core methodology, critical thinking. Biological adaptability allows individuals to face and survive fluctuating environments. Inflexibility, or the lack of adaptability of a society, leads to the necessity of extermination. With critical thinking, people learn from mistakes and challenges to forge newer and more efficient paths in their journey towards a better world. The search for and discovery of newer paths make critical thinking the cornerstone of science.

\section{Popper and science}

What distinguishes science from non-science is not experiment or predictability, but theory. One could undertake a work that changes the whole world, but without theory the work is mere activism, philanthropy, prediction, or exposition. Popper (1996b) insisted, "in the sciences [social and natural], we work with theories [emphasis mine], that is to say, with deductive systems" (p. 75). For the characteristics of a theory see my other book chapter (Cibangu, in press). Deductive systems involve the reflections devoted to the logical consequences of the researcher's statements. Theories are looked at through critical discussion. The goal of science is not to proclaim the universal truths observed and collected from induction, but to be open to the criticism of obtained statements. Critical discussion is based on deductive logic to free the particulars and individualities from the extermination of the whole. In the Popperian sense, the ability to criticize and/or craft a theory is the fundamental method that differentiates science from non-science. This method is also called the trial and error theory or searchlight theory (ter Hark, 2003, 2004a, 2004b, 2006, 2009) of knowledge acquisition. Searchlight theory has the nuance of theory as search of light, and not as a fixed container of truth. We acquire knowledge through the process of trial and error. Though we have natural dispositions to it, knowledge is not something innate, but is discovered through applying a set of theories and constructs to a particular context. Popper first mentioned the trial and error method in his dissertation, explaining that "the method of science is one of tentative attempts (or brain-waves) to solve our problems which are controlled by the most severe criticism. It is a critical development of the method of 'trial and error'" (Popper, 1996b, p. 67). The trial and error method allows for falsification.

According to Popper, the distinct feature of scientific knowledge does not reside in the objective laws of nature and society, nor in the ability to verify and replicate the findings and suggested theories, but in the criticism of proposed theories and related concepts. Falsifiability comes through critical discussion, a method in which particular situations are examined on the basis of trial and error. As Keuth (2005) noted, "every universal statement is falsifiable [emphasis in original]" (p. 31) since there are no monolithic, universal truths. Scientific statements are and should be falsifiable under specific conditions and circumstances. When a statement's, proposition's, or an idea's falsifiability is acknowledged, 
this does not necessarily mean that these statements are useless. Nevertheless, scientists and policy-makers should be aware that the falsifiability of their claims (or some portion of their claims) is probable, instead of simply enjoying the ethos gained by the unchallenged use and occasional imposition of their claims. To be aware of the certainty of falsifiability requires an expectance that critical discussion will aim to falsify, or more precisely, to bring into greater focus the prone-to-error dimensions of obtained statements, decisions, or policies. Falsifiability, not predictability as is often suggested, represents the status of proposed theories, which in turn call for critical discussion in order to yield the most likely answer to problems posed.

Without critical discussion, the Popperian falsifiability or falsification loses its purpose. While falsifiability has been widely known as the marker of Popper's work, it has obscured Popper's epistemological teachings, the most dominant theme of which is the trial and error method of knowledge. It is questionable that most discussions about the social sciences do not address the concept of falsifiability, and simply leave it to philosophers of science. As a result, the broader setting upon which falsifiability is anchored often escapes authors' attention. In sum, important ideas used by Popper $(1959,1972)$ to explain falsifiability are trial and error theory of knowledge, natural selection, and survival of the fittest theory. Crafted in his dissertation, trial and error theory characterizes Popper's methodology. Trial and error method allows a proposed theory to survive the process of natural selection and become the fittest theory. With trial and error being the key criterion of scientific knowledge, one cannot verify, but only falsify theories. Trial and error method ensures the objectivity of scientific work. Popper wrote,

The so-called objectivity of science lies in the objectivity of the critical method; that is, above all, in the fact that no theory is exempt from criticism, and further, in the fact that the logical instrument of criticism - the logical contradiction - is objective. (1996b, p. 67)

Critical discussion comes into existence through inter-subjective exchanges. Critical discussion bridges the space between individuals and thus beyond subjectivity to reach the most truth-like knowledge. As stated earlier, no theory or ensuing institutions should outstrip the centrality and urgency of criticism. Falsifiability concerns all theories involved in the research process.

The question becomes whether one can or cannot criticize ones' philosophical underpinnings, namely: traditions, beliefs, worldviews, convictions, values, goals, standards, and decisions that sustain research. Popper argued that since philosophical underpinnings can prove to have a deep-seated, and often unnoticed, impact upon research and society, they need criticism all the more. He noted, "we also hold theories which we take for granted more or less unconsciously and therefore uncritically; and these uncritically held theories often contain the strongest reason for continuing to hold to other theories consciously" (1983, p. 14). These are all philosophical underpinnings from which we develop and defend other theories concerning reality and the world in which we live. Taken-for-granted theories, so to speak, rule our conscious endeavors. It is worth pointing out that the Popperian critical discussion is not synonymous with agnosticism, a philosophical current that excludes all knowledge. To be clear, Popper did not claim that a truth and a theory cannot and should not be tested, accepted, and maintained as such. Rather he advocated for an open science that always assesses our vulnerabilities and 
attempts newer solutions. Popper did not propound a falsificationistic agnosticism, nor did he propound falsificationism that rejects all truths for the sake of falsifying. Using trial and error theory, he proposed falsifiability for the sake of open society.

Tested theories and/or statements can govern our values and priorities under given circumstances and at a given point in time. "There must be some [emphasis in original] kind of minimum philosophy common to, at least, a great majority of those living in an Open Society a minimum common denominator, leaving room for the mutual toleration of otherwise most diverse philosophies and views" (Popper, 2008, p. 137). Open society does not mean a society void of minimum goals, values, and priorities with which to go about our daily lives. The question remains as to how far toleration should go. This remark takes us to the realization that falsifiability is only a portion of Popper's broader social program.

With trial and error method, theories and human products are not holders of truth, but pointers of light in our endless search for greater light. The vulnerability of our theories is inter-subjectively assessed through the platform of critical discussion. Popper came to the thesis of falsifiability on the basis of the following grounds:

The theory is criticised from very many standpoints in order to bring out those points which may be vulnerable. And the testing of the theory proceeds by its vulnerable sides to as severe an examination as possible. This again is the trial and error method. Theories are put forward tentatively and tried out... Its success depends mainly on three conditions, namely, that sufficiently many and sufficiently different theories are offered, and that sufficiently severe tests are made. In this way, we may secure, if we are lucky, the survival of the fittest theory by a process of elimination [emphasis mine]. (1940, p. 404)6

Popper considered criticism to be a responsible process whereby a person's selected theories, propositions, hypotheses, and constructs are called in question for a better grasp of reality and more productive inquiry. Criticism is directed against a theory's vulnerability. To be precise, in Popper's perspective, one does not hold one's beliefs because they are true and absolute, but because they are true-like and vulnerable. Appraisal of the fittest theory does not eradicate vulnerability. Though it is usually taken as negative, vulnerability conveys the obligations, responsibilities, and challenges that a given theory brings with it. Remember that a closed society does not accept or acknowledge its vulnerable areas. Only in an open society, as discussed earlier, can we capture the points of vulnerability. The temptation, and in fact a disservice to Popper's legacy, is to strive for criticism-proof societies and forget our vulnerabilities and the ability to sort them out. Popper asked us to consider that

Scientific knowledge, and the human rationality that produces it, are, I believe, always fallible, or subject to error... Science and rationality have really very little to do with specialization and the appeal to expert authority... And it is the freedom from intellectual fashions and specializations that make science and rationality possible. (1996a, p. ix)

\footnotetext{
${ }^{6}$ This passage can also be found under a slightly different version of the paper published in Conjectures and Refutations (Popper, 1989, p. 313).
} 
Taken this way, criticism engages with the structures, authorities, and ideas that impede our basic freedoms. A pertinent example is that of accountability, wherein all individuals are answerable for their actions, choices, and values. "Bacon and Descartes set up observation and reason as new authorities, and they set them up within each individual man" (Popper, 1989, p. 17). Fallibilism reminds us that we need to always be aware of how our vulnerability can impact our reason, experience, and observation, and how it has the potential to undermine basic freedoms.

Fallibilism is a significant element ... of the philosophical zeitgeist... It is worth reminding ourselves that Popper and the critical rationalist movement... were responsible for emphasising the limitations of science, and [of] our inquiry more generally... Even our simplest and most successful theories and our most elementary observation statements may be wrong. (Rowbottom, 2011, p. 147)

Despite science's technology-facilitated advances, the claims of scientists carry and induce definite errors. "The insight that all knowledge is fallible constitutes Popper's most formidable contribution to the understanding of science" (Stokes, 1998, p. 43). Though they are among the most commonly touted features of science, rigor, predictability, and experiment cannot override the fact that science, the methods used, the findings obtained, the conclusions reached, and the researchers involved are fallible. It is therefore unrealistic to ignore the inexorably fallible nature of scientific work and its various tools. In much the same way, Popper asserted that we are all vulnerable to falsifiability. ${ }^{7}$ One tends to forget this aspect of vulnerability that Popper clearly mentioned.

Perhaps a term that can help us understand Popper's conception of theories is nets. Popper (1988) wrote, "I see our scientific theories as human inventions - nets designed by us to catch the world" (p. 42). A net is essentially a pliable and removable tool that serves not to kill and destroy, but to allow the flow of water, liquid, air, and the like. The idea implies that a net is not a razor-wired wall with which to hurt and stop humans, but a set of threads through which humans gather ideas to catch and select a specific item for a specific goal. Like nets, theories are removable and pliable. The back-and-forth flow of water (ideas) and the pliability of nets speak to the open universe for which Popper fought. Only through theories as nets, not walls, can the areas of vulnerability be sorted out and brought to light for better actions. What we gain with the metaphor of theory as nets is that theories have holes through which we can take a peek at the future. In this sense, obtained theory does not blind, but enlightens the mind. In other words, the more holes we have in a theory, the more outlets we have to move forward in our journey. Critical discussion seeks to obtain-not absolute containers of truth, but the most vulnerable theories. Popper warned against the myth of agreement when it comes to critical discussion. He maintained that whether agreement is or is not reached, critical discussion brings us closer to the truth. The goal is not to reach agreement or obtain the truth, but to critically examine our undertakings in the hopes of assessing our areas of vulnerability and continuing our journey towards truth. With the metaphor of nets and their holes, theories are pointers to search out truth, but they are not truth in themselves.

\footnotetext{
${ }^{7}$ For further information about falsifiability and fallibilism see Keuth (2005, pp. 31-50), Rosende (2009, pp. 135-154), and Stokes (1998, pp. 25-45), among others.
} 
Popper's biography lays the foundation of his writings. The Nazi domination of societal structures and the ensuing extermination of individuals' lives stand in stark contrast to Popper's overarching theme of open society, science, and universe wherein individuals can criticize social structures, human undertakings, organizations, and suggested theories. Popper did not reject fundamental truths such as basic concepts, goals, values, priorities, and objective realities of ordinary life, but these truths are not by nature immune from critical discussion. Critical discussion does not mean total rejection of tested and accepted knowledge. Instead, it is important to foster an open universe wherein inter-subjective criticism raises newer questions and pinpoints both the fittest and the least vulnerable theories and solutions. Open society has the potential to raise newer questions and try newer solutions. Popper understood open society as an ongoing journey.

\section{Practical considerations}

Let us consider contemporary global problems to see how the idea of open society has played out in our times. How far, for example, can we say our society is open? ${ }^{8}$ Popper listed five contemporary issues that impair the advent of an open society at the global level, namely: (1) world peace (against nuclear weapons), (2) population explosion, (3) bureaucracy, (4) children's education (against media propaganda of sex and violence), and (5) crime. It is impossible to provide a comprehensive list of the challenges, by nation, community, neighborhood, family, and individual, that threaten the open society. It is equally impossible to address these and many other challenges without an open society wherein theories are given as nets that provide further outlets, and not as walls that bar human creativity. Recently, several areas of vulnerabilities have come to the forefront: economic interdependence of our world, dozens of pacific Islands in danger of submersion, increasing weather-induced disasters, relentless incurable diseases, and global poverty. Critical discussion lends itself to be the forum of concerted efforts to make the world a better place. In my view, Popper neglected to give much of his attention to several key issues, including, but not limited to, women, animals, minorities, the environment, indigenous cultures, and the disabled.

\section{Conclusion}

While extensive literature has raised awareness about Popper's idea of falsifiability, it has given little to no attention Popper's social doctrine. Consequently, Popper's legacy figures among one of the most misunderstood topics of our times. To add to this lacuna, a great deal of Popper's material remains unpublished. His thinking is remarkably social, seeking to defend and improve people's lives in an open society, an open world, and an open universe, through an open science. The idea of chosen people is so engrained in our minds that we tend to see a few people as actors on the stage of history and others as recipients and emulators. Open society represents the core tenet of Popper's writings. Against the widespread belief that the social sciences represent a weak form of science, Popper supplied us with a strong sense of the social sciences as being fully scientific, objective, and empirical. It is erroneous to think that the laws of physics do not apply to the emotional and social

${ }^{8}$ See Popper's (2008, pp. 391-393) latest reflections on the open society. 
worlds. Popper attempted to show that science is not solely experiment or rigor, but rather, science generates theory and makes beneficial contribution(s) to the world. Popper suggested a richer understanding of scientific objectivity, which he located in intersubjective critical dialogue. To that end, Popper defended the trial and error theory, searchlight theory, and theory as nets, all of which remain scant in published analyses of Popper's work. Popper was not an agnostic social thinker, advocating falsifiability for the sake of it, and rejecting all form of knowledge. Rather, he advocated the submission of scientific knowledge to critical discussion as part of ensuring an open society. Productive criticism depends upon an open society in which we can freely assess the vulnerabilities and mistakes embedded in our theories to propose newer solutions for fuller human lives. Popper did not prescribe universal recipes for improving human lives; instead, he proposed an open society in which individuals' lives can be fully actualized. Thus, the details of creating and maintaining an open society are left open for further research. These and similar issues cannot be addressed within extant limited engagement of Popper's work. This chapter has shown some of the most important, and, yet, often forgotten themes of Popper's social thoughts.

\section{Acknowledgements}

Special thanks to Carol E. Warrior and Thomas A. Stuby of the University of Washington for their comments on this chapter.

\section{References}

Aristotle. (4th c. BC, 1950). Politics (H. Rackham, Trans.), Harvard University Press, Cambridge, MA.

Aristotle. (4th c. BC, 1924). Metaphysics (W.D. Ross, Trans.), Clarendon Press, Oxford, UK.

Bächtold, M. (2006). An Instrumentalist Criticism of Popper's Propensities. In I.C. Jarvie, K. Milford, \& D. Miller (Eds.), Karl Popper: A Centenary Assessment. Vol. 3. Science (pp. 97-104), Ashgate, Burlington, VT.

Catton, P., \& Macdonald, G. (2004). Introduction. In P. Catton \& G. Macdonald (Eds.), Karl Popper: Critical Appraisals (pp. 1-15), Routledge, London.

Chalmers, F.A. (1985). Methodological Individualism: An Incongruity in Popper's Philosophy. In G. Currie \& A. Musgrave (Eds.), Popper and the Human Sciences (pp. 73-87), Martinus Nijhoff, Boston, MA.

Cibangu, K.S. (2009). Oral Communication and Technical Writing: A Reconsideration of Writing in a Multicultural Era. Journal of Technical Writing and Communication, Vol.39, No.1, pp. 79-105.

Cibangu, K.S. (2010a). Paradigms, Methodologies, and Methods. Library and Information Science Research, Vol.32, No.3, pp. 177-178.

Cibangu, K.S. (2010b). Information Science as a Social Science. Information Research, Vol.15, No.3, June 27, 2011, Available from:

<http:/ / InformationR.net/ir/15-3/paper434.html>

Cibangu, K.S. (in press). Qualitative Research: The Toolkit of Theories in the Social Sciences. In M.A. López-Varela (Ed.), Social Sciences and Humanities: Applications and Theories (Vol. 3), InTech, Rijeka, Croatia, October 25, 2011, Available from: 
$<$ http://www.intechweb.org/>

Gonzalez, J.W. (2004). The Many Faces of Popper's Methodological Approach to Prediction. In P. Catton \& G. Macdonald (Eds.), Karl Popper: Critical Appraisals (pp. 78-98), Routledge, London.

Gorton, A.W. (2006). Karl Popper and the Social Sciences, State University of New York Press, Albany, NY.

Hacohen, H.M. (2000). Karl Popper - the Formative Years, 1902-1945: Politics and Philosophy in Interwar Vienna, Cambridge University Press, New York.

Heine, H. (2006). Ludwig Börne: A Memorial (J.L. Sammons, Trans.), Camden House, Rochester, NY. (Original work published 1840)

Keuth, H. (2005). The Philosophy of Karl Popper, Cambridge University Press, New York. (Original work published 2000)

Lévi-Strauss, C. (1948). La Vie Familiale et Sociale des Indiens Nambikwara, Société des Américanistes, Paris.

Little, D. (1998). Microfoundations, Method, and Causation: On the Philosophy of the Social Sciences, Transactions, Brunswick, NJ.

Malinowski, B. (1984). Argonauts of the Western Pacific, Waveland Press, Prospect Heights, IL. (Original work published 1922)

Micha Ullman (s.d.), October 31, 2011, Available from:

< http:/ / www.galerie-cora-hoelzl.de/artists/ullman.htm>

Mookerji, R. (1919). Local Government in Ancient India, Clarendon Press, Oxford, UK.

Murdock, G.P. (1959). Africa: Its Peoples and their Culture History, McGrawHill, New York.

Popper, R.K. (1940). What is Dialectic? Mind, Vol.49, No.196, pp. 402-436.

Popper, R.K. (Ed.). (1934/1959). The Logic of Scientific Discovery, Basic Books, New York.

Popper, R.K. (1950/1971a). The Open Society and its Enemies: Volume 1: The Spell of Plato, Princeton University Press, Princeton, NJ.

Popper, R.K. (1950/1971b). The Open Society and its Enemies: Volume 2: The High Tide of Prophecy: Hegel, Marx, and the Aftermath, Princeton University Press, Princeton, NJ.

Popper, R.K. (1972). Objective Knowledge: An Evolutionary Approach, Oxford University Press, Oxford, UK.

Popper, R.K. (1956/1983). Realism and the Aim of Science, Rowman and Littlefield, Totowa, NJ.

Popper, R.K. (1956/1988). The Open Universe: An Argument for Indeterminism, Routledge, New York.

Popper, R.K. (1963/1989). Conjectures and Refutations: The Growth of Scientific Knowledge (5th ed. revised), Routledge, New York.

Popper, R.K. (1990). A World of Propensities, Thoemmes, Bristol, UK.

Popper, R.K. (1957/1991). The Poverty of Historicism, Routledge, New York.

Popper, R.K. (1994/1996a). The Myth of Framework: In Defence of Science and Rationality, Routledge, New York.

Popper, R.K. (1994/1996b). In Search of a Better World: Lectures and Essays from Thirty Years, Routledge, New York.

Popper, R.K. (2008). After the Open Society: Selected Social and Political Writings (edited by J. Shearmur \& P. N. Turner), Routledge, New York.

Putnam, R.D. (2000). Bowling Alone: The Collapse and Revival of American Community, Simon and Schuster, New York. 
Reefe, T. (1981) The Rainbow and the Kings: A History of the Luba Empire to 1891, University of California Press, Berkeley, CA.

Rosenberg, A. (2008). Philosophy of Social Science (3rd ed.), Westview Press, Philadelphia, PA.

Rosende, L.D. (2009). Popper on Refutability: Some Philosophical and Historical Questions. In Z. Parusniková \& R.S. Cohen (Eds.), Rethinking Popper (pp. 135-154), Springer, Dordrecht, The Netherlands.

Rowbottom, P.D. (2011). Popper's Critical Rationalism: Philosophical Investigation, Routledge, New York.

Runde, J. (1996). On Popper, Probabilities and Propensities. Review of Social Economy, Vol.54, No.4, pp. 465-485.

Sassower, R. (2006). Popper's Legacy: Rethinking Politics, Economics and Science, McGillQueen's University Press, Montreal.

Sen, K.A. (2005). The Argumentative Indian, Farrar, Strauss and Giroux, New York.

Sen, K.A. (2009). The Idea of Justice, Harvard University Press, Cambridge, MA.

Seneca the younger. (1st c. AD-1st c. BC, 1902). On Clemency (A. Stewart, Trans.), George Bell and Sons, London.

Shearmur, J. (2006). Karl Popper and the Empirical Basis. In I.C. Jarvie, K. Milford, \& D. Miller (Eds.), Karl Popper: A Centenary Assessment. Vol. 2. Metaphysics (pp. 197-210), Ashgate, Burlington, VT.

Stokes, G. (1998). Popper: Philosophy, Politics and Scientific Method, Blackwell, Malden, MA.

ter Hark, M. (2003). Searching for the Searchlight Theory: From Karl Popper to Otto Selz. Journal of the History of Ideas, Vol.64, No.3, pp. 465-487.

ter Hark, M. (2004a). The psychology of Thinking, Animal Psychology, and the Young Karl Popper. Journal of the History of the Behavioral Sciences, Vol.40, No.4, pp. 374-392.

ter Hark, M. (2004b). Popper, Otto Selz and the Rise of Evolutionary Epistemology, Cambridge University Press, New York.

ter Hark, M. (2006). The Historical Roots of Popper's Theory of the Searchlight: A Tribute to Otto Selz. In I.C. Jarvie, K. Milford, \& D. Miller (Eds.), Karl Popper: A Centenary Assessment. Vol. 1. Life and Time, and Values in a World of Facts (pp. 37-56), Ashgate, Burlington, VT.

ter Hark, M. (2009). Popper's Theory of the Searchlight: A Historical Assessment of its Significance. In Z. Parusniková \& R.S. Cohen (Eds.), Rethinking Popper (pp. 175-184), Springer, Dordrecht, The Netherlands.

Urbach, P. (1985). Good and Bad Arguments against Historicism. In G. Currie \& A. Musgrave (Eds.), Popper and the Human Sciences (pp. 133-146), Martinus Nijhoff, Boston, MA.

Verdugo, C. (2009). Popper's Thesis of the Unity of Scientific Method: Method versus Techniques. In Z. Parusniková \& R.S. Cohen (Eds.), Rethinking Popper (pp. 155-174), Springer, Dordrecht, The Netherlands.

Wallerstein, I., Juma, C., Keller, F.E., Kocka, J., Lecourt, D., Mudimbe, Y.V., et al. (1996). Open the Social Sciences: Report of the Gulbenkian Commission on the Restructuring of the Social Sciences, Stanford University Press, Stanford, CA. 
(C) 2012 The Author(s). Licensee IntechOpen. This is an open access article distributed under the terms of the Creative Commons Attribution 3.0 License, which permits unrestricted use, distribution, and reproduction in any medium, provided the original work is properly cited. 